\title{
La cercanía bajo la influencia del virus
}

\author{
Conferencia de Michel Lussault pronunciada en el marco de La Noche de las Ideas. ${ }^{1}$ \\ Formato virtual. 30 de enero 2021. \\ Traducción: Agustina Blanco \\ Revisión: Perla Zusman y Verónica Hollman
}

Michel Lussault

Ecole urbaine de Lyon y École normale supérieure de Lyon. Universidad de Lyon.

Buenas noches a todos y a todas. Estoy muy contento de participar en esta Noche de las Ideas. Les propongo una breve reflexión sobre la cuestión de la proximidad bajo la influencia del virus.

A medida que la pandemia del Covid-19 se instala, el tiempo de confinamiento se extiende y nos encuentra encerrados en casa, recluidos a nuestra esfera privada, forzados a soportar una inacción obligada. Por supuesto que las redes sociales nos brindan la posibilidad de mantener los contactos. Pero, con el paso de los días, nos damos cuenta de que esa sociabilidad digital que se acerca a la parodia carece de algo esencial: aquello que Erwin Goffman (1973) simplemente denominaba "las relaciones en público"; los encuentros cara a cara directos entre humanos desconocidos en copresencia y el contacto concreto con seres de carne y hueso, con quienes nos cruzamos en un entorno espacial que no nos es impuesto como el del domicilio o del trabajo.

Nos falta entonces la exposición al exterior, a ese espacio material y poblado de otros humanos que acogen nuestras acciones $y$, sin el cual, nuestra vida se restringe. Así el mérito de este periodo, si es que cabe reconocerle un mérito, es el de constituir un caso límite que permite recordar que el individuo es un "ser espacial", ya que el espacio sostiene la existencia social (Lussault, 2007). Es la configuración de las materias y las ideas mediante las cuales las vidas humanas son posibles. Es una condición de posibilidad de la existencia. No es una condición a priori, abstracta, sino aquello que constituye una experiencia humana fundamental para cada uno de nosotros, es decir, la práctica espacial de convivencia concreta. Es lo que yo llamo "espacialidad": convivencia concreta con otros individuos y también con los no humanos, objetos y cosas. Por esto mismo, el ser humano también está siempre en un devenir espacial ya que esa convivencia es una actividad incesante.

El ser humano está compuesto de espacialidades que traman su existencia, esta no es una cuestión menor en su constitución como sujeto. Es fácil comprender que una prueba de confinamiento como esta que atravesamos, que coloca la espacialidad bajo un significativo stress, pueda tener impactos también pisco-afectivos en las personas. Así y todo, la convivencia es una actividad difícil. La más mínima de las interespacialidades, es decir, la relación entre seres humanos separados y distantes, confronta al individuo con elecciones que le imponen regular prácticamente un problema de relación con las demás realidades con las cuales se halla en situación. Y esto nos conduce a los cimientos mismos de la dimensión espacial de lo político, si aceptamos el uso que pueda hacer un geógrafo de las reflexiones de la filósofa Hannah Arendt (1995):

(...) el hombre es a-político. La política nace en el Entre- los- hombres, por lo tanto completamente fuera del hombre. De ahí que no haya ninguna substancia propiamente política. La política surge en el entre y se establece como relación. (Arendt, 1995: 45, los resaltados corresponden al original).

\footnotetext{
1 Se trata de un evento mundial que es promovido por el Ministerio de Europa y Relaciones Exteriores de Francia. En Argentina, la quinta edición se celebró entre los días 28 y 31 de enero de forma virtual a causa de la pandemia del Covid-19. La conferencia de Michel Lussault se encuentra disponible en: www.youtube.com/watch?v=wJL1jypFHRI?
} 
Entonces, para Hannah Arendt el campo político surge de la organización de todo grupo humano en reunión de entidades distantes y del consecuente imperativo de implementar procedimientos para abordar ese problema primordial. Hannah Arendt atrae nuestra atención hacia ese espacio tanto material como relacional, lingüístico, simbólico, que separa física, psicológica, mentalmente a los individuos y les impone soluciones tecnológicas, de alguna manera, para establecer los vínculos necesarios para la vida social. Ese principio de separación, ligado a la distancia, constituye a la vez un elemento movilizador, una limitante y un recurso. Sobre la base de aquello que Arendt Ilama "entre-loshombres", los humanos construyen la posibilidad misma de vida en común. Esta noción "entre-loshombres" es muy importante. Para Hannah Arendt las leyes rigen lo político. Es decir, el ámbito entre dos es constitutivo del mundo de los hombres. Ese "entre-los-hombres" crea, a su vez, una distancia y un vínculo, y como tal constituye el espacio dentro del cual nos movemos y nos comportamos unos respecto de otros (Arendt, 2005:170).

Como vemos, la concepción "entre-los-hombres" no es metafórica. Hannah Arendt nos sitúa ante una concepción muy social de la política concebida como relación espacial y, para ello, se vale de un enfoque que otorga a la distancia que separa las realidades humanas una función relevante. Si avanzamos en la reflexión llegaremos a concebir al espacio como la condición que exige que los individuos y sociedades aprendan a pensar, a gestionar, a regular la distancia que separa radicalmente a los seres humanos y, de modo más amplio, que separa toda realidad, distinta sea esta humana o no humana; ser distinto es estar aislado en el espacio.

Del mismo modo, la espacialidad constituye ese "hacer con el espacio", una especie de geopolítica de lo cotidiano que asegura la construcción del sistema relacional y el agenciamiento de las cosas y la gente. Ello permite controlar la distancia y el emplazamiento de cada uno. Hallar la distancia adecuada día a día en nuestras acciones cotidianas elementales, es saber ubicarse, saber ajustar los registros y los usos aceptables del distanciamiento y cercanía. Para cualquier individuo la proximidad procede de este ajuste. A mi juicio, la proximidad es el conjunto de principios que codifican los distanciamientos y las cercanías aceptables para una persona y/o un grupo; distanciamiento y cercanía aceptables que definen la distancia adecuada en una situación dada. En cada experiencia de un espacio cualquiera, se replantea desde cero la puesta en común posible e imposible del espacio que existe entre dos realidades, el espacio que existe entre dos humanos. Este trabajo no se detiene jamás. Es aquello que construye los lugares, calibra su accesibilidad y constituye un potente vector en la dinámica de las sociedades. El "entre-los-humanos" puede abrirse a un compartir más o menos consentido o apacible, pero también, en virtud de circunstancias sociales e históricas, puede convertirse en el terreno físico e ideológico de enfrentamientos, e incluso de rupturas entre individuos o grupos que lo codician de forma simultánea.

Toda la historia de las sociedades está marcada por la potencial conflictividad expresada por el espacio que está "entre-los-hombres" y por la distancia. Tal conflictividad era temida por los antiguos griegos y le dieron el nombre de stasis. Para ellos, la guerra civil destructiva era también un corte del vínculo espacial, una incapacidad para asegurar mediante la regulación de "entre-los-hombres", la definición de la proximidad adecuada, de la coexistencia pacífica entre individuos co-espacializados dentro de la polis/ciudad. La imposición del confinamiento al mundo urbanizado contemporáneo ¿acaso no es una reactualización de aquella stasis siempre posible que amenaza la condición/posibilidad misma de una convivencia en la proximidad? Esto es lo que confiere un carácter relevante y traumático al confinamiento que vacía las calles, las plazas, los centros comerciales, los nudos de intercambio y que impone estrictas normas de distancia interpersonal. Allí donde los espacios nos sorprendían con los cruces, los encuentros y las reuniones, se halla ahora la stasis física sensible y social que vuelve inoperante por doquier esa interespacialidad ordinaria, tan banal como fundamental.

Todos nuestros allegados ahora están lejos; ellos han sido apartados por la pandemia. Y la propia proximidad del contacto está devaluada, se convierte en un riesgo, en una amenaza. Hay que reducirla al máximo. Hay que aislarse, vivir separado de todo 
lo que habitualmente constituye la sociabilidad y la urbanidad. Las autoridades vaciaron y clausuraron los lugares, codificaron la distancia social y, aparentemente, no tenemos otra opción que doblegarnos. La convergencia entre la esfera sanitaria y la de la seguridad es evidente. Se cristaliza en ese consentimiento al encierro residencial inédito que nos toca vivir. Todo individuo confinado, sea cual fuere su categoría social, su género, su edad, está Ilamado a aceptar voluntariamente un control exhaustivo de su hábitat, término que no ha de ser entendido como sinónimo de residencia, sino que remite al espacio de vida de una persona o de un grupo. Así, estamos llamados a aceptar el control de nuestra vivienda/nuestro hábitat, pero también de nuestro habitar, concebido como la actividad que permite componer la propia vivienda/el propio hábitat. Reflexionemos un poco sobre esta noción.

El habitar siempre combina lo que llamo "anclajes", es decir, los espacios sobre los cuales podemos apoyar nuestras vidas cotidianas: los lugares de residencia, de trabajo, de ocio, de las actividades. Por lo tanto, ese habitar combina los anclajes, pero también los movimientos, los desplazamientos de toda índole y las comunicaciones digitales y/o analógicas, como el correo postal, que es una comunicación analógica sumamente importante.

Se entiende de inmediato que las medidas anti Covid-19 producen una alteración generalizada de este habitar, de esta combinación. En efecto, el confinamiento o las medidas de control que hemos de cumplir, por más que no se trate de un confinamiento estricto, ante todo reducen drásticamente la variedad de anclajes de cada persona. El geógrafo Mathis Stock (2006) ha mostrado aquello que él llama la "politopía" del habitar contemporáneo. Esto significa que, debido a la importancia que adquiere de la movilidad, habitamos numerosos anclajes y numerosos lugares. Sin embargo, con el confinamiento nos hemos vistos obligados a renunciar a esta "politopía" en aras/en provecho de lo que llamaría la "monotopía" -y a la que añadiría la "homotopía"-. Resulta que nuestra vida se limita casi exclusivamente a la esfera residencial/ al sitio de residencia. También, en las formas más fuertes de confinamiento, nos vemos reducidos a dar vueltas sobre nosotros mismos. El horizonte prioritario, cuando no exclusivo de cada uno, se torna uno mismo y la relación con la alteridad se encoge, focalizándose así en la célula familiar, expresión que nunca hizo tanto honor a su nombre con esa carga de encierro que se añade por el confinamiento. Nos hemos convertido en nuestro allegado predilecto. ¡Qué situación más curiosa!

Nuestra única referencia continuamente es la mismidad. Literalmente cada día nos reducimos a lo mismo. Ya no podemos experimentar la apertura hacia el otro en los espacios de anclaje extra domésticos, como el de trabajo, al cual no podemos acudir con facilidad, los sitios de recreación que están cerrados, los lugares de consumo que ya no existen del todo, los de cultura también cerrados o los del turismo que están prohibidos. En suma, ya no podemos experimentar la apertura hacia el otro en todos los lugares que frecuentábamos habitualmente. Vivimos una suerte de prisión domiciliaria, no encerrados en un penal, pero como un reo con pulsera, es decir, encerrado en su casa, privado de la libertad del afuera, del movimiento exterior, salvo para alguna salida reglamentada y, por ello, provoca tensión.

El confinamiento no solo nos cerca, sino que también afecta los movimientos, que se ven obstaculizados e inclusive considerados un mal, puesto que ellos son los responsables de la difusión acelerada y mundial de la enfermedad. Ahora bien, hay que recordar que en estas últimas décadas la movilidad fue promovida como un principio, más aún, como un valor social y cultural crucial de la mundialidad. Sin embargo, ahora es juzgada como peligrosa en sí misma y responsable de lo que nos está sucediendo. Se hace un llamado a controlar las fronteras, y los opositores a la mundialización y los soberanistas, apóstoles del control de los movimientos y del estricto control de las fronteras, no se equivocaron y se introdujeron en la brecha abierta por el pánico que se apoderó de nosotros delante de la pandemia.

La conexión comunicacional, sobre todo en su forma digital, parece constituir la única faz del habitar que no ha sido atrofiada, sino que, al contrario, se ha expandido. Inclusive, algunos ven en ella el sustituto ideal del movimiento y de la vinculación 
física entre las personas. Y se les da por imaginar una sociedad en la que se impondrá una nueva forma virtuosa de proximidad sin contacto, es decir, una copresencia mediada por las tecnologías digitales. El "sin contacto" ya se impone como el nuevo estándar en materia de pago y de servicios. Y, para ciertos analistas, poco a poco, se convertiría en el ideal de un vínculo social pacífico y purgado de su potencial amenaza, es decir, la exposición directa al otro.

Se comprende, entonces, que todo esto subvierte el régimen ordinario de la sociabilidad urbana, que en principio se funda en un mínimo de confianza. Digo mínimo y no máximo de confianza, pues el máximo de confianza solo se requiere en grupo de pares que exigen la adhesión de cada uno a un corpus de valores cohesivos. Ese mínimo de confianza asegura que podamos gozar de la fuerza de aquello que yo llamaría las "relaciones de indiferencia", es decir, relaciones efectivas, relaciones de proximidad en las cuales compartimos claramente en un mismo espacio de práctica que es distinto de la propia casa. Espacio de práctica al cual accedemos a través de la movilidad. Pero son relaciones en las cuales no tendremos la carga de asegurar un interconocimiento sostenido del otro. No tenemos la obligación de comulgar con el otro en las mismas creencias, en las mismas ideas y virtudes. Una relación de proximidad en la cual convivimos simple y abiertamente con otros humanos que no hemos elegido ni seleccionado para que sean exclusivamente a imagen nuestra y que tampoco nos es impuesta por ningún tipo de autoridad. No nos sentimos obligados a ser portadores de sus expectativas. No nos sentimos obligados a saber todo de ellos, de sus gustos y sus aspiraciones, del mismo modo que ellos no están obligados a conocer todo de nosotros, de nuestros gustos y aspiraciones.

Esta sociabilidad de proximidad, una sociabilidad de vínculos débiles y contingentes, es la que habilita la convivencia civil. Ella es fundamental para la atmósfera de la gran ciudad. Esa gran ciudad donde el anonimato no es anomia, sino una garantía de la libertad y la emancipación. Aquello que llamamos urbanidad (me gusta emplear el viejo y bello vocablo "urbanidad" para definir la sociabilidad urbana) se funda justamente en ese estilo de interacción espacial, una interacción que jamás está totalmente limitada, sobredeterminada por reglas, por férulas. La concurrencia de una plaza urbana o la visita a un centro comercial es eso. Está reglado, es cierto, pero permanece abierto, sin demasiadas restricciones, sin demasiado orden policial. Ahora bien, el régimen de espacialidad, legitimado por el confinamiento, instaura lo inverso a esa relación de indiferencia. En efecto, el confinamiento instaura la sistematización de la desconfianza. La exigencia de la distancia social y de los gestos preventivos postula de algún modo que el otro, cuando está cerca, es una amenaza, que conviene desconfiar, guardar una distancia prudencial. Un analista pesimista descubrirá allí la difusión de una ideología comparable, en menor grado desde luego, a la famosa y funesta dialéctica del amigo-enemigo, que forma parte del núcleo de la teoría política de Carl Schmitt (1994). El propio vecino deviene en un enemigo posiblemente malhechor, aun sin quererlo, ya que puede ser portador sano, contagioso, inocente claro está, pero de quien, de todas maneras, hemos de protegernos. Por supuesto que el confinamiento actual no crea ex nihilo esta tendencia. Por lo demás, todo gran período epidémico vuelve a poner el tema en la contienda.

Además, el mismo analista pesimista al que aludía anteriormente destacará que hace tiempo se ha comprobado, con la vuelta del soberanismo y el populismo, el éxito de la idea de que el otro representa una amenaza. Esta idea en boga, a menudo, va de la mano del repunte de la imaginación positiva, de la autoctonía, que también registra un éxito singular en estos tiempos. El otro es aún más peligroso si viene de otra parte. La alteridad geográfica redobla entonces la alteridad social y cultural. En ese marco de pensamiento hoy difundido por todo el mundo, lamentablemente el único prójimo aceptable sería aquel que es mi homólogo.

Nuestra alerta actual vinculada con la pandemia, el confinamiento que nos toca vivir, refuerza, empero, el atractivo de estas mitologías programadas de la desconfianza y de la valoración de lo autóctono. Eso les confiere un nuevo alcance, pues converge con decisiones políticas, sanitarias y de seguridad que son presentadas como ineluctables e 
La cercanía bajo la influencia del virus MicheL LUSSAULT

incuestionables por estar fundadas en la medicina. Y allí encontraríamos algunas intuiciones y demostraciones de Michel Foucault cuando piensa, en particular, el concepto de "biopoder". Lamentablemente, en el marco de esta conferencia no tenemos tiempo para abordar la pertinencia y el alcance del trabajo de Michel Foucault (2004) para esta reflexión sobre el confinamiento y sus efectos políticos.

Para concluir, observamos y acompañamos desde el inicio de la pandemia la implementación de lo que llamaría "geopoder", es decir, un sistema de ideas, instrumentos, prácticas e instituciones legítimas que pretenden organizar la vida espacial y regular nuestra proximidad. Es un "geopoder" de crisis, obviamente, pero podemos preguntarnos si no estará diseñando las posibles orientaciones para el futuro de la convivencia. La cuestión geopolítica que se nos plantea entonces es elemental y esencial a la vez: ¿qué quedará de la urbanidad, una vez pasada esta prueba pandémica? La pregunta que se deriva inmediatamente de esta es ¿qué cohabitación vamos a poder/querer asegurar y asumir? ¿Sabremos degustar sin reservas las relaciones de proximidad sin coerción, esas relaciones de cercanía sin límites a las que estamos habituados y que tanto sabor dan a la vida urbana? ¿Saldremos de esta prueba más solitarios o más solidarios? Si bien estas preguntas quedan abiertas, me parece que cabe plantearlas.

\section{Gracias por su atención.}

\section{Bibliografía}

»Arendt, H. (1995). Qu'est-ce que la politique? [¿Qué es la política?]. París: Seuil.

» Arendt H. (2005). Journal de pensée (1950/1973). [Diario Filosófico (1950/1973)]. París: Seuil.
» Foucault, M. (2004). Securité, territoire, population. Cours au Collège de France. 1977-1978. [Seguridad, Territorio, Población. Curso en el Collège de France (19771978)]. París: Seuil/Gallimard.

》 Goffman, E. (1973). La mise en scène de la vie quotidienne (Vol. 2, Les relations en Public). [La presentación de la persona en la vida cotidiana]. París: Minuit.

» Lussault, M. (2007). L'homme spatial. La construction sociale de l'espace humain. [El hombre espacial. La construcción social del espacio humano]. París: Seuil.

»Schmitt, C. (1994). La notion du politique. [El concepto de lo político]. París: Calmann-Lévy. (Edición original 1934).

» Stock, M. (2006). L'hypothèse de l'habiter poly-topique: pratiquer les lieux géographiques dans les sociétés à individus mobiles. EspacesTemps.net. Recuperado de: https://www.espacestemps.net/articles/hypothesehabiter-polytopique/

Michel Lussault / michel.lussault@ens-lyon.fr Geógrafo, profesor de la Universidad de Lyon (Escuela Normal Superior de Lyon), miembro del laboratorio Medio Ambiente, Ciudad, Sociedad (Universidad de Lyon/CNRS). En su trabajo analiza las modalidades de habitación humana de los espacios terrestres, a todas las escalas y partiendo de la idea de que el antropoceno urbano globalizado es el nuevo hábitat de referencia para todos y cada uno. En 2017, creó la Escuela Urbana de Lyon, que dirige actualmente. Es autor de L'homme spatial. La construction sociale de l'espace humain (2007) (traducido al español como El hombre espacial. La construcción social del espacio humano. Buenos Aires, Amorrortu, 2015), L'avènement du Monde. Essai sur l'habitation humaine de la terre (2013); Hyper-Lieux. Nouvelles géographies de la mondialisation (2017); Cartes d'identités. L'espace au singulier (con Yann Calberac, Olivier Lazzarotti y Jacques Lévy, 2019) y Chroniques de géo' virale (2020). 